\title{
GRADUAL MORPHOLOGICAL EVOLUTION IN A LATE CRETACEOUS LINEAGE OF PLANKTONIC FORAMINIFERA
} KUCERA, Michal*; MALMGREN, Björn, A., Department of Marine Geology, Earth Sciences
Centre, University of Göteborg, S-413 81 Göteborg, Sweden.

The morphological evolution in the Late Cretaceous planktonic foraminiferal genus Contusotruncana is since long known to be characterised by a steady increase with time in test conicity leading to the development of highly spirocovex $C$. contusa from its flatter ancestor $C$. fornicata. In the present study we analysed quantitatively the changes in shape and size in this lineage during the last 3 m.y. of the Cretaceous at DSDP Site 525 from the South Atlantic Ocean. Forty-eight samples were taken from a $50 \mathrm{~m}$ thick section of upper Maastrichtian nannofossil chalks from Hole 525A. The specimens were mounted and oriented and their outlines in spiral and edge views were digitised. As a measure of test size we used the spiral outline area; to express the test shape the following variables were used: spiral roundness, conicity and triangularity in edge view, total number of chambers and number of chambers in the last whorl. Additionally, we recorded the proportion of sinistrally coiled specimens and the proportion of kummerforms in each sample.

Specimens of the studied lineage were found to be dominantly dextral ( $>95 \%$ in most samples). A significant positive correlation between test size and total number of chambers was revealed both within particular samples and in successive sample means. Similarly, the edge outline triangularity is positively correlated with test conicity both within samples and throughout time. Our data provide the first quantitative evidence for gradual evolution in the $C$. fornicata- $C$. contusa lineage. Changes in mean values (calculated for all specimens in the samples) of selected variables are shown below:

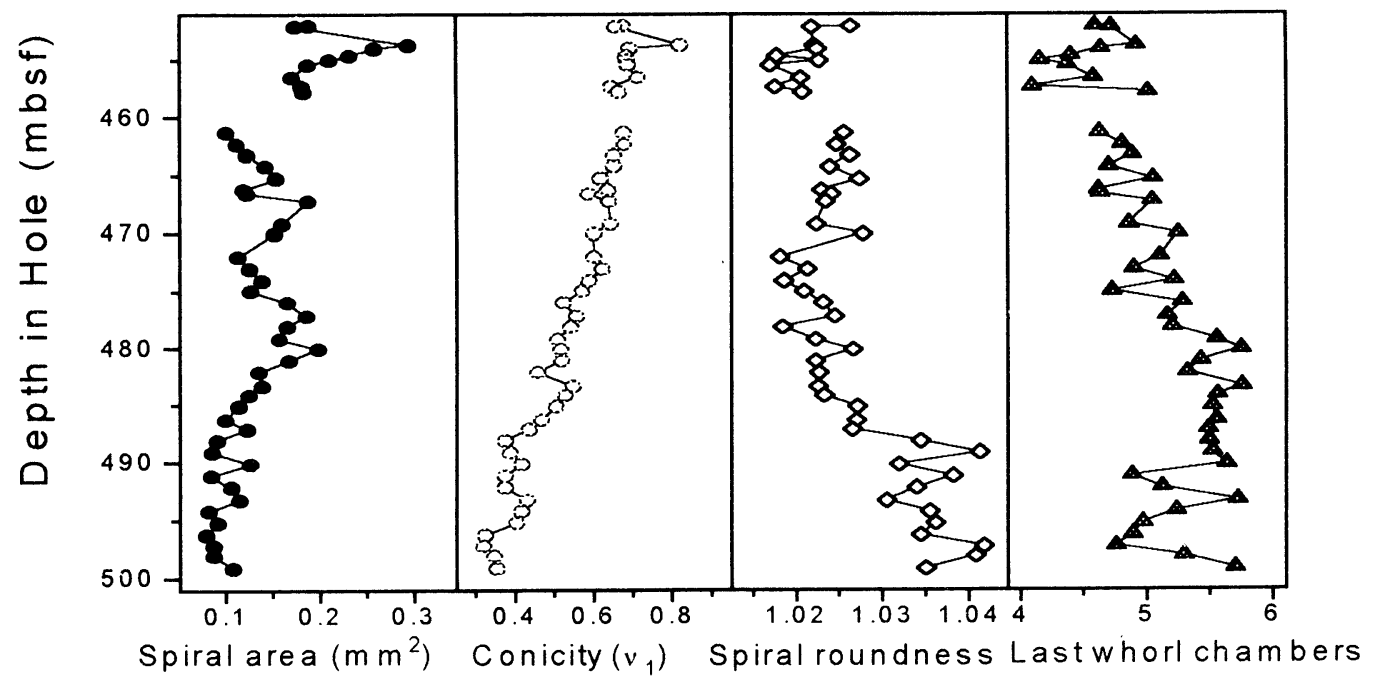

After a period of random fluctuations a synchronous change in several parameters took place during the lower part of the magnetic chron $\mathrm{C} 31 \mathrm{~N}$, at the depth of about $485 \mathrm{mbsf}$. The mean number of chambers in the last whorl started to decrease, while the mean test conicity started to increase. The lobate spiral view outline became more rounded and the mean test size increased. At the same time the proportion of kummerform specimens increased almost twice reaching values over $50 \%$. The gradual changes in test conicity and number of last whorl chambers then continued throughout the terminal Cretaceous until the species became extinct at the K/T boundary. Although most of the samples analysed can be assigned to either $C$. fornicata or $C$. contusa, some samples contain purely transitional paleopopulations which can be assigned to the respective species only arbitrarily. 